\title{
HUMAN SEXUALITY, ETHICAL ISSUES AND THE MEDICAL PROFESSION
}

Derek G. Gill, Ph.D.

University of Missouri-Columbia

Mid-American Review of Sociology, 1982, Vol. VII, No. 2:3-28

In 1979 the estimated number of births to unmarried women was 597,800, an increase of almost ten percent from 1978. This increase is a composite of the rising number of single women in the population as well as an increase in the rate of childbearing among these women (U.S. Department of Health and Human Services. 1981). Moreover, the rise in illegitimacy almost certainly understates the extent of this form of reproductive behavior. Illegitimate births can also occur to women who are separated or still married if the husband is not the putative father. Notwithstanding the Supreme Court's policy of June 1977, that federal law does not require states to spend Medicaid funds for so-called "non-therapeutic" abortions, the number of abortions for that year also rose compared with 1976 (U.S. Department of Health, Education and Welfare, 1979). Clearly, if one assumes that the vast majority of abortions and illegitimate births are the result of unplanned and/or unwanted pregnancies, many women and their sexual partners fail to control their fertility; a set of circumstances of interest and concern not only to primary care physicians but to society as a whole.

Not only has illegitimacy increased but the estimated proportion of pre-nuptial conceptions, first-born children to women within eight months of marriage, has also increased. The pre-nuptial conception rate is not routinely calculated for American vital statistical data, but information for the period 1940-1965 shows an increase in both illegitimacy and prenuptial conceptions over this period. The situation is unlikely to have changed dramatically between 1965 and the present day. 
These increases in illegitimacy and pre-nuptial conceptions are suggestive of changes in patterns of sexual behavior and adjustment, presumably indicative of a fundamental change in attitude towards sexuality, compared with the attitudes and behaviors prevalent in the years preceding World War II. Moreover, such changes in patterns of sexual behavior have not been restricted to the United States. Rising rates of illegitimacy and pre-nuptial conceptions have been apparent in many other complex western industrialized social systems such as Scandinavia, the United Kingdom and Western Germany.

The intention here is to (1) examine the nature of these changing patterns of sexual behavior, (2) discuss the ethical factors which are applicable to sexual interaction and (3) to relate these two issues to the duties and responsibilities of physicians when interacting with individuals and families.

\section{CHANGING PATTERNS OF SEXUAL BEHAVIOR AND ADJUSTMENT}

Contemporary patterns of sexual behavior and adjustment cannot be examined in vacuo since they have been erected upon and presumably are affected by earlier patterns of behavior and underlying attitudes. It will not be possible here to provide a complete historical account of changes in attitudes toward sexual behavior but some reference to the last century is necessary if a foundation for an understanding of the contemporary situation is to be laid. The attitudes of the Victorians towards sexuality will be examined as they relate to the various components of sexual behavior and as they impinge upon current forms of sexual interaction. In this way previous patterns of sexual behavior and adjustment will be demonstrated and the changes which have occurred over the last one hundred and twenty years or so will be illuminated by the socio-historical perspective.

\section{Components of Sexual Behavior ${ }^{1}$}

While it is theoretically possible to distinguish between biological and social aspects of sexual behavior, in practice it is difficult to maintain the distinction. Masters and Johnson
(1969:10) have stated that: "sexual functioning is a natural physiological process yet it has a unique facility that no other physiological process, such as respiratory, bladder or bowel function, can imitate. No other physiological process can claim such malleability of physical expression." Thus, at the extreme, religious sects that have demanded and enforced celibacy upon their adherents have indeed been able to eradicate overt sexual expression from the incumbents' lives. As we mature sexual responsiveness emerges and, if it is not extinguished, the way in which the physical tensions are released is influenced by social conditioning. The development of the sex drive and sexual responsiveness in both males and females is, therefore, dependent upon learning, an outcome of the sexual and sex role socialization to which young people have been subjected. Masters and Johnson's work on "Human Sexual Inadequacy" (1970) suggests that women who have been reared in a climate of opinion where sexual response has been defined as sinful may be unable to respond either emotionally or physiologically to heterosexual stimulation.

In these two cases the maturation of the sex drive is so affected that sensations of pleasure and enjoyment associated with physiological tension release will either prevent it from developing or, if they emerge, are considered not quite nice or even sinful. These attitudes toward sexual behavior, that sexual activity is not permitted to the occupation of priesthood and that sexual behavior is sinful, stemmed from the beliefs and ideologies of certain kinds of religion. Sexual behavior has been viewed as a sacred aspect of human life:

The Roman Catholic view...holds that sex is sacred and inherently good. But its sacredness lies in its being the specific means of reproduction. Whenever, then, sexual intercourse takes place in a manner calculated to frustrate the sacred purpose of reproduction, the sacred act is profaned (Turner, 1970).

Other aspects of the Judeo-Christian religious tradition display a much more severe attitude toward sex. St. Paul's view seemed 
to be that this particular "sin of the flesh" was the most serious temptation with which Christians had to deal. Abstinence was the only safe mechanism for avoiding its destructive influence but if this was impossible then sex inside and only inside marriage was just acceptable so long as intercourse was not accompanied by enjoyment. ${ }^{2}$ It is doubtful whether this view of sex as sin and as inherently unpleasant is accepted by more than a limited few today, but as recently as 1960 Lee Rainwater in his book, And the Poor Get Children: Sex, Contraception and Family in the Working Class, showed that for many working class women this indeed was their perception of sexual behavior. Nevertheless such a view was reflected in the attitudes of many groups in the nineteenth century.

Although the learned nature of the sexual response cycle in both male and female is now recognized after the work of Masters and Johnson, in the nineteenth century the prevailing attitude both in the medical profession and the population at large seemed to be that sexuality was natural for men but only occurred among women when their passions were unnaturally aroused.

If sex is defined as sinful and unpleasant then its overt expression, instead of generating feelings of pleasure and enjoyment, may be accomplished through a sense of duty, even painful duty. In these circumstances sex accompanied by pleasure and enjoyment was natural for the male but unnatural for the female. Such attitudes, as I shall show later, are imbued with a double standard of sexual morality and one which, while condemning sexuality in general, could nevertheless condone covertly if not overtly commercialized sex and the exploitation of lower class females. ${ }^{3}$

Sex as duty and pain associated with sexual behavior, while closely linked with the idea of sex as sinful and the double standard of sexual morality, involves another element of sexual behavior, sex as reproduction. If sexual intercourse always takes place without benefit of contraception then the act itself may become associated with anxiety, disaster or even fear, particularly by women; the fear and anxiety stemming from the stresses and strains induced by frequent childbearing. In these circumstances women "do their duty" by their husbands and derive no pleasure for themselves from the act. Indeed in some working class groups the definition of a good husband is one "who does not bother me too much," meaning one who makes infrequent demands for sexual intercourse. But this attitude toward sexual behavior need not stem only from the fear of excess reproduction. It may also be associated with the view that sex is sinful and, less dramatically, with the process of sexual socialization in which information about sex is restricted; when information is provided and attitudes to sexuality are exposed, sex is defined as something not quite nice, something, in fact, about which nice girls do not concern themselves. These are circumstances not conducive to the development of pleasure and enjoyment during sexual maturation and eventual sexual experience.

Today, whereas some women may still look upon sexual behavior with disfavor, the majority can acquire the necessary knowledge and skills of sexual techniques in an atmosphere in which repugnance and fear can be ignored. Consequently:

Sexual relations in marriage are less concerned with procreation than with providing mutual satisfaction and support within the marital relationship, a change made possible by the development of simple and effective methods of contraception (Illsley and Gill, 1968).

Love defined "as a strong emotional attachment, a cathexis between adolescents or adults of the opposite sexes, with at least the components of sex desire and tenderness" (Goode, 1959), can now be expressed through contracepted sexual intercourse without fear, at least without fear of conception. Sex is now often defined as a pleasure and, if a mutually satisfactory relationship is not achieved, the aggrieved partner may consider this to be sufficient grounds for dissolving the relationship. ${ }^{4}$

While certain aspects of current patterns of and attitudes towards sexual behavior are of relatively recent origin, others are part of a process of change stemming from the nineteenth 
century if not before. To what extent have contemporary attitudes toward human sexual behavior been newly developed or are they simply an extension of perspectives already nascent in the Victorian era? I shall describe, generally, the Victorian sexual scene, drawing both upon contemporary sources and the work of historians interested in the nineteenth century. Both sources carry the chances of an over-monolithic middleclass interpretation of Victorian patterns of sexual activity. It is hoped that the application of the discussion of sexual behavior developed above will serve to emphasize rather than obscure the complexities of the Victorian attitudes toward sex.

\section{SEX IN THE NINETEENTH CENTURY}

Much has been written about the strict code of sexual behavior said to be characteristic of the Victorian era-roughly the period from 1850 to 1900 . In polite Victorian society the subject of sex was strictly taboo. Women were to be protected, placed on pedestals where their elegance and beauty could be admired, but only in an atmosphere completely devoid of sexual overtones. The only instruction in sex that a middleclass Victorian girl could expect was, "you must do your duty to your husband." What this "duty" was, was seldon made clear, but the atmosphere in which the instruction was conveyed implied that it was something unpleasant which women had to put up with. Before marriage the middle-class girl was closeted and confined, her virtue protected with as many rules and restrictions as the ingenuity of Victorian society could produce. Ignorance of what was to be expected in marriage seemed to be a necessary part of the upbringing of women from the middle and upper socio-economic groups. Crow (1971:29) provides the following illustration: "Legs were referred to as the lower appendages" or sometimes as "lower limbs" if the conversation had taken a slightly racy turn. Even the legs of furniture were sometimes covered with long draperies lest their shape give offense. Young men and women were simply not permitted to meet in private. Chaperones, chosen from older and embittered spinsters who had missed out in the marriage market, were admirably fitted for the role of policewoman in the parlor or ballroom.

These restrictive attitudes toward sexual behavior were supported by eminent members of the medical profession, particularly in Great Britain, but mirrored by American medical practitioners; for example Dr. William Sanger's report on the history of prostitution in the United States published in 1859, throughout reflected dubious statements derived from Sanger's own moral repugnance for the subject of his study. In Sir William Acton's treatise on the "Functions and Disorders of the Reproductive Organs in Youth, in Adult Age and in Advanced Life Considered in their Psychological, Social and Moral Reactions," the view was advanced that normal women have no sexual feelings. But more generally the whole attitude toward sexuality expressed in this book is one of fear and disgust. Sex was barely tolerated for the purpose of reproduction, lip-service was paid to its use as an expression of love, but reciprocity of enjoyment between the sexes was suspect if not abhorrent (Comfort, 1968). On the contrary, excessive sexual activity was seen as positively dangerous and the development of sexual precocity was to be prevented at all costs. Comfort (1968) declares that:

Within two generations (from the publication of Acton's book) masturbation, previously regarded variously as a sin or an unmanly habit, had been elevated to a major cause of insanity, impotence and disease; and a note of ascetism different from, but almost as extreme as that of Alexandrian monasticism had become the normal tone of hygiene instruction. The overswing was slow to pass (it has not gone yet), leaving the medical man last among the social and biological scientists to admit the diversity of normals in the range of human behavior.

Similar views were expressed by other leading medical figures, by Sir William Willis, Superintendent of Hamwell Asylum, by Dr. Hare in 1861 and even as late as 1895 Henry Maudsley was still claiming a relationship between mental disorder and selfabuse. $^{5}$ 
But alongside this oppressive climate of opinion there existed a degree of sexual license in American society which has not been exceeded since. In New York, for example, in the 1850 s it was estimated that the city supported 7,860 prostitutes (Sanger, 1919). Broadly speaking the prostitutes were organized into three, as it were, social class groupings servicing respectively the needs of the upper and upper-middle classes, the middle classes and the lower classes. The upper echelons often operated from highly expensive brothels and houses of assignation which were plushly appointed in accordance with the tastes of their upper class clientele. Henriques (1963) in the second volume of his three volume study of prostitution devotes five chapters to an analysis of prostitution in the United States and demonstrates quite conclusively the extent to which prostitution and exploitation of lower class females was part and parcel of American life both in the nineteenth century and through the present day. Indeed the development of the frontier lands probably would not have been completed without the institution of prostitution. From Denver to California and from north to south as the nineteenth century progressed, brothels were an important part of boom towns, mining areas, transportation concentration points and so on. Initially the expansion of the frontier generated very high ratios of males compared with females in the early developmental phases. The lust for a woman seemed to be as important as the search for gold and other precious minerals and resources. Inevitably the system of prostitution long established on the eastern seaboard expanded westward as economic opportunities arose. Moreover we now realize, unlike the assumption made by Dr. Sanger and other students of prostitution in the nineteenth century, prostitutes did not have higher rates of mortality than their more sanctimonious confreres. On the contrary it was some of the prettiest and best-developed women who tended to be successful in the professional game. These women were young, healthy and fit and therefore well-equipped to stand the rigors of their trade. Rather than leaving the ranks of prostitution through death and disease the major "wastage rate" seemed to be associated with either marriage or re-entry into a more formal occupation usually at a relatively high level. ${ }^{6}$

In the slave states, not surprisingly, the exploitation of women for sexual purposes took on a very different format. Black women as slaves, were of course, the property of their masters. Here the double standard of sexual morality was operationalized at a very overt level. Plantation owners and the middle and upper classes would place southern women on elite pedestals which extolled the virtues of the southern belle while utilizing their female slaves as outlets for "normal" and "natural" male sexual activity and aggression. Moreover such unions between whites and their female slaves had an additional advantage since progeny of such unions then became the possession of the master and simply served to increase his overall slave capital. With this "tradition" of sex exploitation behind them it is perhaps not surprising that, when after the Civil War many blacks migrated northward into the growing urban areas, black women entered institutions of prostitution in numbers far greater than their proportion in the population would lead one to expect.

By the late nineteenth century prostitution in New Orleans had become big business. The bordellos and houses of assignation were organized on the three class system reminiscent of Sanger's description of New York prostitution in the 1850s. In the twentieth century as organized crime began to be an important component. of American political and social life criminal exploitation of prostitution became even more evident. $^{7}$

Clearly the ideals of innocence and restraint in sexual behavior portrayed by the medical profession and supported by at least some middle-class parents, contrasted strongly with the opportunities for men to have access to prostitutes in more or less openly recognized brothels. This divergence of views received tacit acknowledgement, even support, from the establishment. ${ }^{8}$

For many American males during much of the nineteenth century and even into the early twentieth century prostitutes represented an important vehicle for sexual outlet. Moreover, 
resort to prostitutes seemed to be characteristic of just about all classes of American society. Certainly there is ample evidence to suggest that many of the more reputable brothels and houses of assignation dealt exclusively with middle and upper class clientele. The upper-class clientele, however, were in part responding to a pattern of sexual behavior already well established in the eighteenth century. The experience of the young middleclass bachelor, with late marriage and resort to the brothels for sex as pleasure and enjoyment to release physical tension in the teens, the twenties and even into the thirties, may have encouraged the view that sexual activity varied according to location and partner. Sex for enjoyment was to be found in the brothels, with a mistress, actresses, chorus girls or with any other "available" women, often including servants; and sex for reproduction in the family. ${ }^{9}$ So while many husbands and wives probably enjoyed their sex lives it seems reasonable to assume that some did not. The differential patterns of sexual socialization created the circumstances where, in marriage, it was often impossible for the female to experience pleasure during intercourse. This in turn suggests that the pleasure potential of the male was reduced and that his enjoyment would be heightened if both were capable of experiencing pleasure in the act. One of the ancient skills of the prostitute is to simulate feelings and expressions of pleasure during intercourse with her client. An authority such as Havelock Ellis had no doubt that married men formed a numerically important part of the client population of the better class nineteenth century brothels. And Henriques, (1963), in his exhaustive historical account of prostitution draws a similar conclusion; some men preferred the expensive but more exciting embraces of prostitutes to the cold submissive tolerance of their wives.

The relationships between sex as love, sex as property and sex as reproduction created even more problems for the nineteenth century middle-class. W.J. Goode in two very important articles $(1959,1963)$ has shown that love is a socially produced phenomenon and that the way in which it is expressed is dependent upon differing definitions of appropriate love objects. (It will also be argued that the way in which sexual love can be expressed is also affected by technological factors-the effectiveness and availability of contraceptive techniques-a situation more relevant to the circumstances of today, which I shall develop in greater detail later.) Goode goes on to show that in middle and upper class families where the transference of property rights and the maintenance of status are important considerations, parents try to exert close control over their children's choice of marital partners. Victorian middle-class attitudes and patterns of sexual behavior had to fit in with these requirements as well as establish satisfactory ways for dealing with sex as enjoyment and physiological tension release, and sex as reproduction. This was relatively easy to do for the woman. It was achieved by insisting that women did not find sex pleasurable and did not need it to release physical tension. Sex was seen as a duty to which they had to respond. As children approached sexual maturity controls were introduced to reduce the likelihood of their developing attachments to individuals whose status was not that of a potential marriage partner. During the search for a satisfactory partner the males had recourse to the brothels for sex as pleasure; when marriage subsequently ensued, only if both sets of parents were satisfied with the other's son/daughter, could a relationship begin. If mutual affection and a loving relationship developed, all well and good, but if not the concept of duty to one's parents and to the line of inheritance was sufficient motivation to form a basis for the marriage. Moreover free expression of a loving relationship through sexual activity was limited by the need to control family size, unless of course the inheritance of either or both partners was sufficient to indemnify the young couple against the costs of an unregulated number of children. Love as a strong emotional attachment, a cathexis, might be established but its physical manifestation through marital intercourse seems to have been limited.

\section{SEX IN THE TWENTIETH CENTURY}

Given this set of circumstances the significance of contraception is now apparent. Before the advent of effective contraceptive 
techniques it was clearly impossible to distinguish between sex as reproduction, sexual intercourse as pleasurable and as the physical manifestation of a loving relationship. Put more bluntly: people were unable to exercise control over the consequences of their sex lives. Developments in contraceptive technique in the twentieth century have created the possibility for both integration and differentiation of sexual behavior. Sex as reproduction can now be isolated from sex as love or of sensuality. Married couples can now enjoy the sensual pleasures of intercourse, of sex as a release from physiological tensions, as well as a method of demonstrating the emotional love relations (so beloved by women's magazines) without having to concern themselves with the possibility of conception and the fears which the relationship between sex and reproduction previously engendered. But it is also necessary to examine the input of changes in attitudes toward human sexuality and the emergence of new patterns of sexual behavior upon women's roles. Associated changes in the status of women may impinge considerably on their life styles and life chances, generate new definitions of women's roles, and lead to further change in patterns of sexual behavior. These processes in turn may have a feedback effect, adding pressure to expand contraceptive services, and encouraging research to develop even more effective contraceptive techniques as well as inducing more liberal attitudes towards abortion. These processes and the hypothesized mechanisms of interaction may be represented diagrammatically (see Figure 1).

Attitudes toward marital sexuality have undoubtedly changed and certainly at an accelerated rate since the Second World War, but a shift to less restrictive rules and regulations was discernible earlier. The flappers of the 1920 s were beginning to toy with a more liberal code of sexual behavior, but the movement did not become generally acceptable. It is just possible that young women of the twenties and thirties encouraged by improvements in the sphere of women's political rights, felt that the time was right to attempt similar moves toward sexual equality, but it would seem that public opinion was still too traditional to accept such a radical concept. Constance Rover
Figure 1

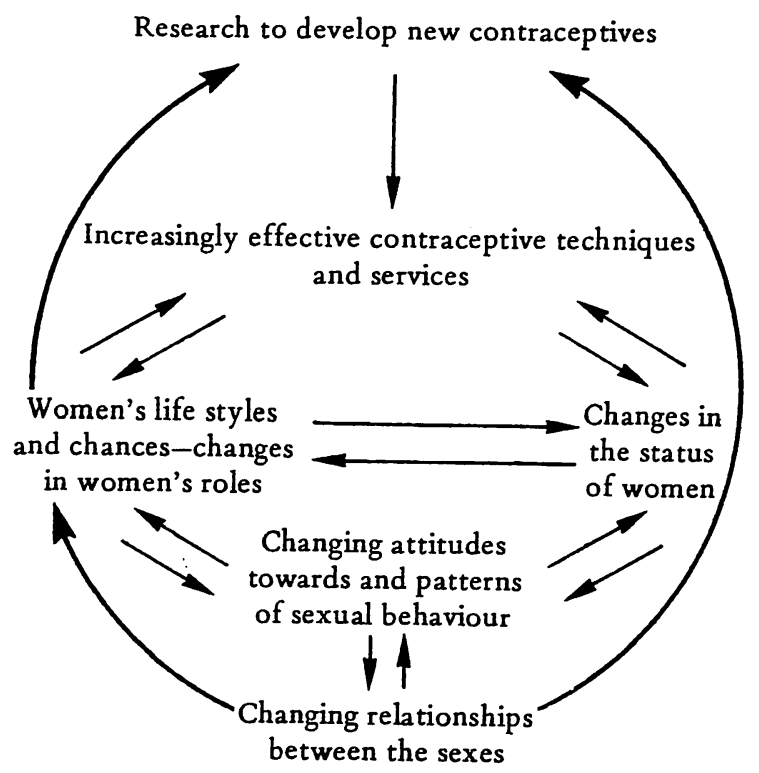

(1970) has ably demonstrated how wary were the emancipationists of an attempt to link demands for political and sexual equality. While some improvement in women's political rights occurred during the first decades of the twentieth century a massive concern for women's sexual rights did not emerge until after the Second World War.

Contraception also attracted rather negative attitudes in the early part of the twentieth century. By the 1920 s middleclass people and perhaps some skilled manual workers were already using condoms or diaphragms to control the size of their families, but many members of the medical profession and certainly the establishment in general remained unconvinced of the desirability or the morality of such procedures. Sections of the lower social strata were apparently reluctant to use contraceptive techniques and pockets of resistance still persist today. 
The first Kinsey Report (in 1948) and the work of Rainwater (from 1960-1965) provides some data which may help to explain the apparent reluctance of working-class couples to control their family size. Both authorities noted that sexuality among workingclass males may be associated with aggressive attitudes. Aggression is part of the normal experience of working-class children particularly since their parents are much more likely to use physical chastisement as a disciplinary measure than their middleclass counterparts (Wootton and Illsley, 1970). Middle-class life styles provide ample opportunity for the men folk to demonstrate their masculinity. The middle-class husband and father has adequate opportunity to exercise realistic control over objects, situations and often other people. Even routine non-manual workers who are often placed in a subordinate position can identify vicariously with middle-class standards of manipulation and control. Their masculinity is therefore not threatened, but the working-class male is in a much less satisfactory position. At work he is often controlled rather than being the controller. Security of employment is less certain as economic forces rather than his own efforts determine job opportunities or even the possibility of employment. Wage differentials between men and women in the unskilled and less attractive occupations, although present, can be quite small, and, if his wife goes out to work, the threat to his status as the wage earner and chief support of his family is undermined. In periods of economic depression it may be easier for women than men to find work. When opportunities for masculine expression are limited, the ability to demonstrate virility. by keeping one's wife pregnant may become one of the most important avenues still open for the confirmation of maleness; consequently contraceptive techinques are ignored. This possibility, in combination with a working-class tradition of a less taboo ridden attitude toward sexual intercourse may help to explain an early reluctance of working-class groups to exercise effective control over family size.

The Contemporary Scene

The redefinition of sexual behavior combined with Betty Friedan's (1965) attack upon the feminine mystique have helped to promote the women liberation movement's challenge to those institutionalized features of contemporary social systems which have been erected upon or contain certain elements of the traditional distinctions between the sexes. In this sense the movement has been attacking one of the basic institutions of societythe family-because it places upon women the basic responsibility for the care and upbringing of children. Men in the past have been largely absolved from this responsibility and there is no logical or biologically inviolable reason why this should continue to be so. Nevertheless the institution of the family and its task allocations are so traditionally entrenched that many aspects of socio-economic relationships and processes would have to change if the conditions are to be created in which men and women could contribute equally to the demands of child rearing and socialization. It is too early to anticipate the possible outcomes of this confrontation, but there is no doubt that women have more power now that they can control their own fertility. If the movement achieves coherence, unity and massive support, then it would be a brave person, male or female, who would be prepared to predict what the future organization of society
would look like.

The contraceptive revolution, the consequent redefinition of sexuality and the growth of the women's liberation movement of course have implications for sexuality outside as well as inside marriage. Pre- and extra-marital intercourse need no longer be accompanied by the fear of conception which in the nineteenth century effectively supported the conventional code of sexual morality. Today, sexual intercourse represents a virtually free choice situation. No longer is it possible to erect, proselytize and maintain universal do's and don'ts in sexual behavior. ${ }^{10}$

Nevertheless, society still condemns certain aspects of sexual behavior. While sexual activity, actual or simulated, may be permitted on the stage and the screen, indecency charges would almost certainly be brought against persons engaging in sexual intercourse in other public places. Moreover, the consequences of premarital intercourse when the result is an illegitimate child, are still stigmatized although much less severely than in earlier periods. It therefore follows that so long as intercourse 
takes place beyor ${ }^{\prime}$ the public gaze and the possibility of conception is eliminated, only the participants need to be concerned with the personal and private morality of the act. An effective contraceptive technique also protects both partners during the bargaining activity, in terms of reciprocity and exchange, which culminates in sexual intercourse. The woman need not fear illegitimacy if either she or her partner chooses to discontinue the relationship; the man need not fear the public or private consequences of acknowledging or denying paternity. Whatever other constraints may affect the union, the bargain struck between the participants may be negotiated without fearing the possibility of conception. Essentially, the couple need only satisfy themselves on what constitutes an appropriate relationship for the expression of love and for the enjoyment of sensuality for them to proceed to sexual intimacy. ${ }^{11}$

The limited analysis of sexuality, contraception and the status of women presented here generates a set of guidelines within which medical practitioners can operate when interacting with patients concerning issues and situations related to human sexuality and reproduction. Changing patterns of and attitudes towards sexual behavior clearly create a situation of uncertainty for the physician. Under these circumstances a set of guidelines are doubly valuable.

Sexuality, Morality and the Role of the Physician

Thus far it is evident that while patterns of and attitudes towards sexual behavior have changed markedly in recent decades, these changes have been less dramatic than some commentators, particularly in the mass media, would have us believe. A complete sexual revolution has not occurred in American society, rather a less taboo-ridden societal attitude to human sexuality has gradually emerged, particularly since the end of World War II. While the double standard of sexual morality is adhered to less forcefully today, it can still make life miserable for many women. While illegitimacy is less strongly stigmatized today, unmarried mothers still face severe economic, social and psychological deprivation for bearing a child outside marriage. In these circumstances the physician needs to be prepared to react to a variety of situations, circumstances and attitudes when interacting with patients where aspects of human sexuality pertain, directly or indirectly, to a consultation.

Most medical schools now provide some instruction on sexual behavior. The coverage tends to be highly varied but at least current generations of physicians are not totally unprepared to deal with aspects of sexual behavior when relating to their patients. The brief socio-historical analysis of sexual behavior presented above will now be utilized to provide some guidelines for physicians which, hopefully, will provide a basic set of parameters around which primary care physicians in particular may organize their thoughts concerning human sexuality.

Today sexual themes pervade many aspects of American life. Products as diverse as automobiles and shaving cream are advertised and presumably sold through a process which invokes, either covertly or overtly, sexual imagery. Sexual imagery and direct sexual content is to be observed in popular songs, in cinema, on television and in contemporary novels. However, accurate information on human sexuality is much less universally distributed, especially among young people. Sex education programs in schools are often poorly developed and deal only perfunctorily with the 'difficult' issues, such as abortion, contraception, sexual exploitation and so on. Studies in Great Britain have shown that parents want human sexuality to be dealt with in school in an overt and realistic fashion (Gill, Reid and Smith, 1971; Rogers, 1974). For example, mothers in Aberdeen wanted a sex education program in school to deal with subjects as contentious as: 'Pregnancy. Before Marriage,' 'Sex and Love,'. 'Sexual Morality' and 'Birth Control and Family Planning' (Gill et al., 1971). Even more surprising was the fact that, while the mass media, particularly the press, presented sex education as a highly contentious issue and suggested that most parents would not support instruction on sexuality in school, the Aberdeen mothers surveyed were strongly supportive with eighty percent unreservedly in favor of such programs. Similar studies, so far as I am aware, have not been conducted in the U.S., but there often seems to be a pessimistic attitude toward the development of such programs. On the other hand, school districts in the 
'progressive' states on the eastern and western seaboards have introduced sex education programs which deal with contentious issues.

Physicians, of course, enjoy high status and prestige and are often influential figures in the communities they serve. Moreover, they possess the necessary body of knowledge to provide the resource for informing the pupils on the physiological and anatomical aspects of human sexuality. In the nineteenth century, physicians often developed a most incomprehensible attitude to human sexuality whereby their moral prognostications supported the status quo, supporting the double standard of sexual morality from a narrow religio-philosophical base. Today one hopes the profession is less prejudiced and more knowledgeable. Indeed in many respects physicians now have both a moral and economic responsibility for supporting and encouraging the development of sex education programs in school. The moral responsibility derives from their knowledge of sexual anatomy and physiology and their role in the prescription and/or monitoring of contraceptive techniques. The knowledge that physicians acquire during their training makes them the ideal purveyors of such information in the school setting. Indeed it probably makes good pedagogical sense to utilize physicians to impart factual knowledge on human sexuality to school children. Their economic responsibility for undertaking such tasks stems from the economic support which most medical students enjoy, either directly or indirectly, when in medical school. Both Federal and State resources today make significant fiscal contributions to medical education and it seems reasonable that future generations of physicians should repay some of this assistance by accepting public responsibility in sex education.

Family practitioners and other primary care physicians are only too well aware of the tragedies, economic, social and psychological, that can be associated with human sexuality. At the start of this essay attention was drawn to the large number of unwanted pregnancies which occur in the United States today. Sex education programs in school may be defined as primary prevention. The pupils need to receive sex education in a climate of opinion which states that sexual intercourse should never take place without benefit of contraception unless both participants mutually agree that if a child is conceived it is wanted by both partners. ${ }^{12}$

While contraceptive technology has improved markedly in recent decades, most currently available contraceptives suffer from a particular disadvantage; to be effective one or both partners must anticipate the act of sexual intercourse. Unpremeditated acts of intercourse are sometimes exposed to the risk of conception; a kind of sexual Russian roulette. Presumably, many illegitimate pregnancies and pre-nuptial conceptions are conceived in this manner. Abortion provides a resolution mechanism for such unpremeditated pregnancies and also for those pregnancies which occur through contraceptive failure. In these circumstances an abortion may be viewed as secondary prevention. Abortion therefore becomes a rational mechanism for eradicating unwanted pregnancies.

In the Western world where the Judeo-Christian religious tradition has been particularly strong and pervasive, the issue of abortion has attracted much attention with protagonists stating their positions with intense emotionality, often at the expense of rationality. Anti-abortionists generally base their case on the assumption that 'humanness' begins at conception: once the zygote forms then a human life should be assumed to exist and any procedure that destroys the zygote or the subsequently developing fetus is considered murder. Extreme conservatives on this issue take the position that even if the mother's life is in danger the procedures which would save the life of the mother by directly destroying the fetus, are inadmissible. Such a position clearly echoes the double standard of sexual morality as well as reflecting the second class status of women in human society since time immemorial. If women are to achieve real equality in modern society it is difficult to see how this can be achieved unless they are able to control their own bodies, (Boston Women's Health Book Collective, 1976). Control over their own bodies necessarily implies the inalienable right of a woman to choose whether or not to carry to term the products of conception. ${ }^{13}$ Lest physicians succumb to the same moralistic imperialism characteristic of the profession during the 
Victorian era, the decision to terminate the pregnancy is the mother's alone. Moreover the moral right is also her's alone. The physician, therefore, should not force his or her view of morality on a patient, and has a responsibility to refer her to another physician if incapable of complying with her decision.

\section{CONCLUSION}

While this analysis of human sexuality and associated ethical issues is necessarily brief it has hopefully, provided some guidelines within which physicians may relate to their patients concerning human reproduction, its consequences and antecedents. It, therefore, seems appropriate to draw together the main elements of the arguments presented above and to relate them to the day-to-day practice of medicine.

I have argued elsewhere (Gill, 1978) that the physician/ patient relationship is characterized by an inevitable and continuing imbalance of power which, among other things, is due to the esoteric body of knowledge acquired by the physician over eleven years (at the least) of training, which is inaccessible to and often incomprehensible to the patient. If this is true, physicians have an over-riding moral responsibility toward patients to correct, as far as is possible, this imbalance of power.

In the area of human sexuality this imbalance of power is as apparent as it is in other areas of medical practice. In addition, the physician is dealing with highly emotive topics which are also characterized bÿ an imbalance of power or even of exploitation. Women have been, since time immemorial, second class citizens in Western society. Both their sex and their sexuality has been continuously exploited, sometimes with the implicit if not explicit support of the medical professions. The moral responsibilities of physicians in the area of human sexuality therefore become truly awesome.

Under these circumstances it seems reasonable to impose upon the medical profession in general and primary care physicians in particular the following responsibilities: (1) to inform their patients and, where possible, the communities they serve, of the bio-medical aspects of human sexual behavior in a morally neutral atmosphere and (2) to aid and assist women to achieve independent control of their bodies and their sexuality.

Despite the so-called sexual revolution, individuals, couples and groups are often still affected by taboos which define sexuality as a subject which is 'not quite nice.' Physicians can and must play a part in dispelling these attitudes and help their patients and communities to adopt a more rational attitude toward human sexuality. They must therefore avail themselves of every opportunity to discuss matters pertaining to human sexuality whenever the possibility of so doing arises, either individually or collectively. After all, both individuals and groups may still be reluctant to discuss human sexual behavior. Physicians through their training control a body of knowledge which is absolutely essential to informed discussion of human sexual behavior. It is, therefore, their responsibility to take the initiative to promote further discussion of such issues, for the social, psychological and economic parameters in which human sexuality takes place are forever changing. It is not, however, their responsibility to impose moral decisions concerning sexual behaviors.

\section{FOOTNOTES}

1. This and the following two sections draw in part on: Gill, D.G. (1977). Illegitimacy, Sexuality and the Status of Women. Blackwell, Oxford, especially chapters VI and VII.

2. See Young, W. Eros Denied, Weidenfeld and Nicholson, London, 19.65 for a masterly exposition of the development of restrictive attitudes towards sexual expression.

3. Engels (1973) took the view that monogamous marriage, and what he claimed to be its inevitable accompaniments, adultery and prostitution, originated in the emergence of private property. Women became defined as possessions and were devalued to the level of objects rather than having personalities in their own right. Once women had been so defined they could be used as sexual objects, and as unpaid domestic servants. The origins of the institutions of private property and monogamous marriage are still not understood, but recently Marxist-feminists have begun to analyze the relationships between patriarchy and capitalism much more thoroughly (Diamond and Mueller, 1980). The 
definition of women as property and their subjugation to the authority and dominance of the patriarch generates the circumstances in the sexual arena, whereby their sexual behavior is controlled. Thus women can be used as sexual objects in societies as different as Eskimo groups where visitors may be offered the services of the patriarch's wife, or early European society where lower class females were frequently exploited for sexual purposes. Out of such conditions arose elements of the double standard of sexual morality which persists even today. See Kate Millett's Sexual Politics, Avon Books, New York, 1971, especially Part 2, Historical Background, the Sexual Revolution, First Phase, and the Counter Revolution, pages 59-234, for an excellent analysis of many of the components of the double standard of sexual morality.

Thus, today, younger women may still not take the initiative in the early stages of heterosexual interaction; they are still dissuaded or prevented from dating a young man. In the nineteenth century the double standard of sexual morality was much more in evidence, but the fact that it continued into the twentieth century and still exists today, albeit in a less extreme form, is abundant evidence of its persistence. Much more socio-historical research needs to be carried out before the etiology of the double standard of sexual morality can be completely understood; but some of the elements of sexuality outlined above, sex as sin, sex as a private property and the differential nature of human sexual response, are likely to form part of the explanation.

4. Further confirmation that sex does play a more overt, probably a more crucial role in the relationship between the sexes is provided by the frank discussion of such matters in modern mass media and by the appearance of and great demand for "marriage manuals"-a euphemism for texts providing instruction in sexual techniques and the psychology of sexual adjustment. In more recent years even the euphemisms have disappeared from the titles of books on sex techniques and in both Europe and the U.S.A. films depicting sexual behavior are screened in public cinemas, whereas in the recent past such pictorial displays were restricted to private clubs or were simply illegal.

5. It is uncertain to what extent Victorian parents took seriously these dire consequences of masturbation and tried to stop their children's attempts to masturbate, but devices to prevent onanism were advertised and marketed in the $1860 \mathrm{~s}$ and $1870 \mathrm{~s}$, and as recently as 1930 a respected English medical catalogue still offered for sale belts designed to prevent male and female self-abuse. Similar products were also offered for sale on the eastern coast of the United States in the first decades of the twentieth century.
6. The frontier brothel tradition is preserved even today in the state of Nevada where, in 1973, thirty-three such houses operated in rural areas and small towns containing between them something like 225 to 250 prostitutes (Symanski, 1974).

7. The association between illicit sexual activity and alcoholic consumption is as old as the profession. The prohibition era in the United States was a natural extension of the links between the hotel, the illicit liquor industry and organized prostitution. Conveniently illegal, both prostitution and alcohol consumption became closely associated in the "speak-easies," clubs and clip joints as organized crime developed during the prohibition era.

8. We've already seen that even in the nineteen eighties formally organized brothels are permitted in the state of Nevada. Massage parlors, often euphemisms for brothels, are found in most cities of any size in the United States. From time to time members of the establishment in the form of elected city officials, etc. attempt to clamp down on organized prostitution even to the extent of closing down brothels and houses of assignation that soon reappear, either in new locations or by simply closing their doors, waiting until the heat was off and then reopening.

9. Even in Victorian novels dealing with overtly sexual themes, such as Mrs. Gaskill's Ruth, Wilkey Collins' No Name, and Michael Sadler's Fanny By Gaslight, there is never any suggestion that women could actually enjoy intercourse, an idea utterly repugnant to contemporary nineteenth century commentators.

10. The continuing redefinition of sexuality both at present and in the recent past is reflected by different attitudes towards sex and love expressed in contemporary popular songs (Carey, 1969). After a content analysis of the words of such songs for the years 1955 and 1956, Carey (1969:728) noted that: "One of the most conspicuous changes is in the conception of love." The 1966 songs created the impression that permissiveness with affection was being replaced by attitudes which supported permissiveness without affection. Sexual intercourse was valued for itself and was no longer submerged in or associated with a rather hazy notion of romantic love. Choice as regards sexual behavior seemed to be emphasized, whereas the earlier songs description of sexuality tended to be fatalistic. In the earlier songs people were said to "fall in love" practically independently of their own desires, in marked contrast to the views expressed in the 1966 lyrics that opportunities for sexual expression and love were to be actively sought. Even a cursory examination of the hits of the 1970s and the early 1980s would suggest that these tendencies have been strengthened rather than reversed. 
The almost continuous process of redefining sexuality and the development of new attitudes toward sexual behavior since the end of the Second World War is documented further by the work of Zube (1972). Her analysis of selected issues of The Ladies Home Journal over the period 1948-1969 revealed "discernible shifts in the expression of certain value orientations" (385), particularly in relation to sexual morality. Tentative steps towards a new form of sexual morality emphasizing individual circumstances rather than a rigid adherence to previously accepted standards are taken in the articles appearing in the late sixties. Consequently statements about what is or what is not acceptable in terms of sexual behavior can have no general application, since they represent only the bias and prejudices of the individual or groups from which they stem. Sex has become a subject for negotiation between the parties to the act. Morality in relation to sexual behavior therefore becomes idiosyncratic, individualistic, and is only the concern of the participants.

11. One reservation must however be applied to the argument developed here. A few women are choosing to conceive and rear a child withou establishing a permanent relationship with a single partner. This necessarily introduces a consideration of factors which affect the third party to the act, the child. Given the present stigmatization of illegitimacy and illegitimate children, the mother is in fact gambling that attitudes will change or that she will be able to combat effectively society's condemnation of reproduction outside marriage throughout child rearing and socialization. Who can be certain, in this situation where "acceptable" sexual behavior is in a state of flux, that such an attitude is unduly optimistic?

12. The initial technology to prevent unwanted pregnancies has existed since the late 1890 s and has become increasingly effective over the last two decades. The adverse consequences of unwanted pregnancies and births have been adequately documented. What rational code of ethics could deny the application of a technology, contraception, which would eradicate such adverse consequences? Clearly the perserverance of religious codes or other mythologies which deny righ of access to contraception are irrational given the prevalence of social activity. Where such beliefs persist they cannot, of course, influence the practice of medicine which is, at least in part, based upon the principles of logic and rationality.

13. An earlier version of this paper contained 7 pages which refuted, by utilisation of the concept "person-hood" the anti-abortionists' proosition that human life begins at conception. Persons interested in receiving copies of this discussion may contact the author and they should also consult Engelhardt (1975-1976) and Tooley (1976), details of which are given in the bibliography.

\section{REFERENCES}

Boston Women's Health Book Collective

1976 Our Bodies, Ourselves: A Book by and for Women. Revised 2nd ed. New York: Simon \& Schuster.

Carey, J.T.

1969 "Changing Courtship Patterns in the Popular Song," American Journal of Sociology 74(6):720.

Comfort, A.

1968 The Anxiety Makers. London: Panther Books Ltd.

Crow, D.

1971 The Victorian Woman. London: George Allen and Unwin Ltd.

Diamond, $T$. and Mueller, $A$.

1980 "Linking Patriarchy and Feminism: Issues in Marxist-Feminist Theory, Harvard Educational Review, 50(1):70-79.

Engelhardt, H.T.

1975 Bioethics and the Process of Embodiment," Pers. in Biol. \& Med, 18(4):486-500.

1976 "The Ontology of Abortion." In S. Gorovitz et al. (Eds.), Moral Problems in Medicine, New Jersey: Prentice-Hall, pp. 318 334

Engels, F.

1973 The Origin of the Family, Private Property and the State.

Frieden, B.

1965 The Feminine Mystique. London: Penguin.

Gill, D.G.

1978 Limitations Upon Choice and Constraints Over DecisionMaking in Doctor/Patient Exchanges. In E. Gallagher (Ed.) The Doctor/Patient Relationship in the Changing Health Scene. Washington, D.C.: U.S. Department H.E.W., Fogarty International Center, 017-040-004214

Gill, D.G., Reid, G.D.B and Smith D.M.

1971 “Sex Education, Press and Parental Perceptions." Health EducaGoode, W.J. tion Journal, March, p. 1.

1959 "The Theoretical Importance of Love." American Sociological Review 24:38.

1963 "The Process of Role Bargaining in the Impact of Urbanisation on Family Systems," Current Sociology 21(4):535.

Henriques, $\mathrm{F}$.

1963 "Prostitution in Europe and the New World. Volume two of: Prostitution and Society, London: MacGibbon \& Kee.

Illsley, R. and Gill, D.G.

1968 "Changing Trends in Illegitimacy," Social Science and Medicine $2: 415$. 
Mid-American Review of Sociology

Masters, W.H. and Johnson, V.E.

1969 "Human Sexual Response," J. \& A. London: Churchill Ltd.

1970 "Human Sexual Inadequacy," J. \& A. London: Churchill Ltd. Millett, $\mathrm{K}$.

1971 Sexual Politics. London: Rupert Hart-Davis.

Rainwater, I.

1960 And the Poor Get Children. Chicago: Quadrangle Books.

Rogers, R.S.

1974 Sex Education: Rationale and Reaction. London and New York: Cambridge University Press.

Rover, C.

1970 Love, Morals and the Feminists. London: Routledge and Kegan Paul.

Sanger, $\mathrm{W}$.

1919 History of Prostitution, its Extent, Causes and Effects Throughout the World. New York: New Edition.

Symanski, R.

1974 "Prostitution in Nevada," Anns. Assoc. American Geographers $64(2): 357-377$

Tooley, M.

1976 "Abortion and Infanticide. In S. Gorovitz et al. (Eds.), Moral Problems in Medicine. New Jersey: Prentice-Hall, pp. 297-317.

Turner, R.H.

1970 Family Interaction. New York: John Wiley and Sons.

U.S. Department of Health, Education and Welfare

1979 Center for Disease Control. Abortion Surveillance, September.

U.S. Department of Health and Human Services

1981 Advance Report of Final Natality Statistics, 1979. Monthly Vital Statistics Report 30(6) Supplement 2.

Wootton, A.J. and Illsley, R.

1970 Social Iñfluerices on Parents and Their Children. In R.G. Mit chell (Ed.), Child Life and Health. J. \& A. London: Churchill.

Young, W.

1965 Eros Denied. London: Weidenfeld \& Nicholson.

Zube, M.J.

1972 “Changing Concepts of Morality: 1948-1969," Social Forces $50(3): 385$.

\section{THORSTEIN VEBLEN: A NEW PERSPECTIVE*}

Barbara E. Ryan

Washington University

Mid-mmerican Review of Sociology, 1982, Vol. VII, No. 2:29-47

In spite of his extensive writings, Thorstein Veblen is an American sociologist most students of sociology know very little about. The obscurity of Veblen's work within the discipline is explained by two parallel trends: the selective utilization of his economic theory, and the failure to legitimize or develop his generalized social theory. Veblen's sociology explains class divisions under capitalism as outward manifestations of the desire for dominance in order to gain self-esteem and prestige. The division between pecuniary and industrial occupations illustrates this process; however, the first and most important division from which all others follow is the division between the sexes. The lack of acknowledgement in sociology of Veblen's emphasis on the primacy of the sex role division in the development of human society suggests an inquiry into either the legitimacy of his position and/or academic selection which rejects the importance of sex role divisions.

Through an examination of both Veblen's writings and later analysts of his work, this paper (1) reclaims Veblen's sex role analysis, (2) demonstrates male bias in the social sciences, and (3) considers the applicability of Veblen's theory with contemporary feminist theory.

Thorstein Veblen was an economist and sociologist who regularly incorporated anthropology, philosophy, and psychology into his numerous written works on American society during the early 1900s. In his writing, Veblen transforms keen analytical observations of "normal" social structure and processes into cynical social criticism. To develop his ideas, nearly every aspect of social, economic, and political life is examined; thus, his topics included capitalism, bureaucratization, occupations, education, sex differentiation, government policy, economic structures, and class divisions.

*I would like to express my appreciation for the encouragement the late Alvin Gouldner provided on an earlier draft of this paper and my thanks to John Zipp for his many helpful comments and suggestions on the final version. 